\title{
Blockchain and IoT Technology in Transformation of Education Sector
}

https://doi.org/10.3991/ijoe.v17i12.25015

\author{
Parul Agarwal ${ }^{1}$, Sheikh Mohammad Idrees ${ }^{2(\bowtie)}$, Ahmed J. Obaid $^{3}$ \\ ${ }^{1}$ Jamia Hamdard, New Delhi, India \\ ${ }^{2}$ NTNU, Trondheim, Norway \\ ${ }^{3}$ University of Kufa, Kufa, Iraq \\ sheikh.m.idrees@ntnu.no
}

\begin{abstract}
Technology has impacted every field of life, and Education sector is no exception. It has seen seismic changes off-late. The traditional classroom teaching-learning process involved teachers and students using the black-board approach. But the past years have seen a change in dynamics of this process. Technology has crept in and has profoundly changed it for better. On one hand, when traditional classrooms had teachers, students and books as players, the current classroom has teachers, students, robots, e-books, laptops and books as the players. Today's classrooms have enabled the teaching-learning process cross boundaries in the form of e-lectures and tutorials. Massive amount of Information is readily available for the process. Also, a shift from "Teacher-centric" to "Student Centric" can be seen in the current scenario. Several technologies have been key-players in revolutionizing the education sector, but the focus of this paper is concentrated in exploiting the applications of Blockchain and IoT in the sector and identifying the areas where they prove to be beneficial. An extensive literature survey shall be done to understand and identify how these technologies are a solution to major educational problems. The teaching learning process needs to be understood with respect to various parameters: change in process, change in players, change in outcomes derived, and others. The associated challenges shall also be identified. A detailed analysis of these enables us to conclude that these technologies, can revolutionize the education sector for better in future, particularly Blockchain is young, but owing to the benefits derived from it, further research and adoption shall for surely change the teaching-learning process.
\end{abstract}

Keywords-e-learning, teaching-learning, outcomes, classroom, environment, customized lecture plans, security, campus

\section{$1 \quad$ Introduction}

Technology is a powerful tool that has the potential to transform the teaching-learning process. In traditional classrooms, the teachers teach and the students receive. The modern classroom has seen a paradigm shift. The whole process is two way, due to technological advances. It has redesigned the learning space (both physically and virtually) and thus introduced new models and techniques of teaching-learning 
and accommodated new relationships among its stakeholders. These technologies in education include IoT [1], Blockchain [2], Artificial Intelligence [3], and Cloud Computing [4]. These are the driving technologies that shall bring a digital transformation. They are recognized as enablers or innovations that can improve business processes, create new business solutions, and alter the way all sectors operate today. Blockchain, is a digital distributed ledger and can store records like a register [5]. IoT can create user-friendly solutions in any sector in which it is used. These technologies are dependent and interconnected to achieve best results. In some time, we will see the convergence of these technologies. Blockchain initially emerged as an enabler in financial payments using Bitcoins [6], and Ethereum. But last few years have seen its applications in other sectors [7] as well like Supply chain management, and for maintaining digital identities [8-9]. Some recent works have seen how Blockchain can be combined with IoT for improving the infrastructure of IoT devices [10-11]. In [12], the authors provide the benefits of these technologies and illustrate using a use-case. They also mention how these technologies complement each other. This paper discusses the potential of Blockchain and IoT in education, while analyzing its applications, benefits and challenges associated with both.

The paper is structured as follows: Section 2 discusses the applications of Blockchain technology and IoT in education thereby enhancing the teaching-learning process. It also discusses the associated benefits we derive from them. Section 3 discusses the challenges associated with these applications. Section 4 provides a conclusion while identifying the future applications of these technologies.

\section{Blockchain and IoT for education: applications and benefits}

\subsection{Blockchain for education}

Blockchain, is the technology being used to generate cryptocurrencies, and is based on digital, and distributed ledger concept, where blocks represent the transactions and contain data about them. Presently, it has its applications in finance, with crypto-currencies being Bitcoin, Zerocash, and Ethereum, etc. The most common amongst these being Bitcoin. Though, Blockchain technology is young, yet, is being adopted owing to the success Bitcoin is being adopted world-wide. It is immutable, transparent, secure and trust-worthy for all transactions in Blockchain network, and thus, has applications as discussed in [13-14]. Owing to these advantages, researchers all over the world have applied it to several areas, but, its potential in Education has been discussed in [15]. Blockchain enables its participants to perform transactions over a robust network at an affordable cost [16]. Properties of a Blockchain based network are Scalability, Reliability, strongly resistant to alteration, and Decentralized. It is based on the concept of Public Key cryptography. In this concept, each participant creates two keys- a public and private. Public key may be understood as email address which can be known to others on the network. The private key is like a password, which is not known to all and deciphering it is a tedious task. For every public key, there exists a private key. Assume, A needs to send a message to B. B first shares the public key with A. A then sends the message encrypted with that public key to B. Only, B can decrypt that message with 
the Private key known to B. In the similar fashion, Blockchain technology performs transactions between A and B. For every transaction, to be carried out, a block is generated by obtaining some certain number of nodes. The block contains all the transactions that occurred between A and B. Also, a digital signature [17], is used for robust authentication. Each transaction is bound by a timestamp value. As the transactions grow, and the values get updated, a new block is created which gets linked to the original block. All the players of the transaction each have their own copy of the block-chain. Robust cryptographic algorithms, and SHA-256 Hash functions prevent any tampering of original data and incase, an attempt is made by the third party, it would be denied. A typical Blockchain based transaction scenario is illustrated in Figure 1.

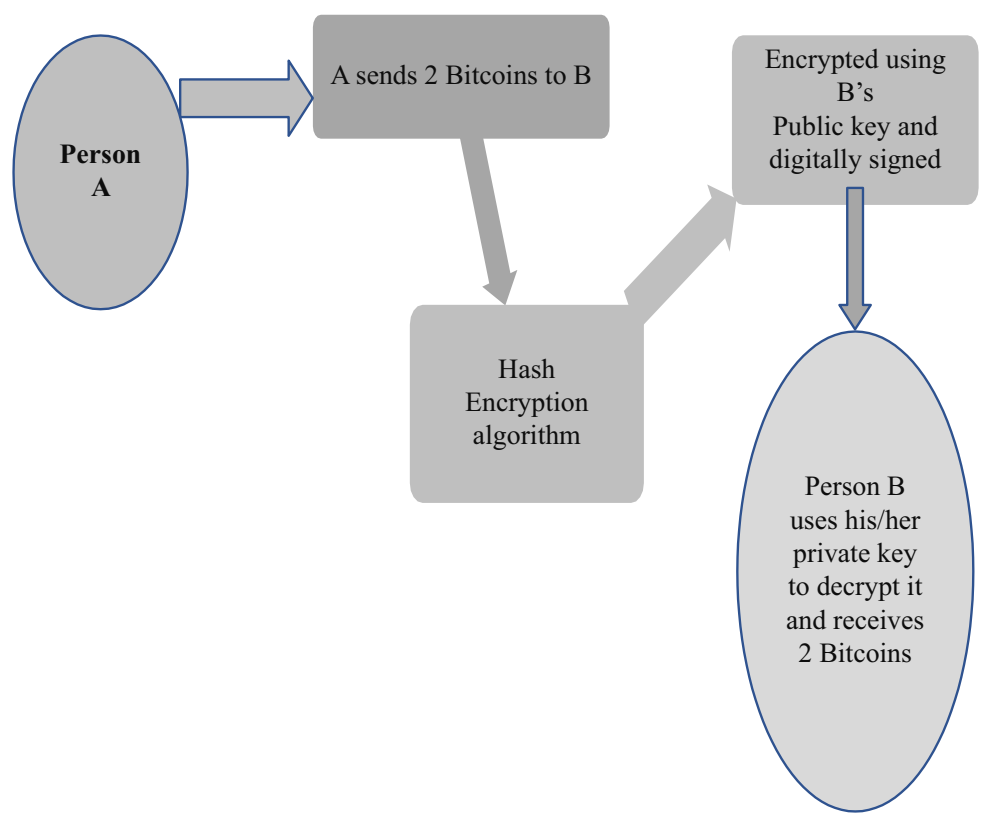

Fig. 1. To demonstrate a Blockchain-based transaction

Applications in education. The prime application of Blockchain technology is management of certificates. This includes handling and providing storage of academic credentials including transcripts, certificates, academic documents, degrees, etc. Blockchains can be used to issue unique digital assets that verify the credentials of academic degrees and certifications. A high level of privacy, and trust can be provided for the same. The study in [18] uses the decentralized property of Blockchain in order to provide verification and issuing of official transcripts. Though, the data records will be visible to all, but accessibility, and modification is permitted only to authorized individuals or organizations. MIT media Lab, and Learning Machine Co. collaborated to provide open infrastructure for storage, viewing, and verifying blockchain based certificates management. Also, universities are known for providing cloud storage to students, and teacher. But, the existing cloud storage facilities like the Amazon DropBox are quite expensive. This cost incurred is usually minted from the students in the 
form of very high- tuition fees. Projects like Filecoin, and SiaCoin reduce the cost related to storage. They give out unused storage spaces in organizations for the same to academic institutions and in exchange get cryptocurrencies. Besides, Sony Global education also creates a platform for the same. Blockchain in a broader perspective, can be utilized to redesign the teaching- learning process, and keep track of its implementation in the sector. Each student can be uniquely identified using his/her ID. The block would also store extra information, like location, Class performance, project evaluation, etc. This would then enhance the learning outcomes and also help improve the learning experience. Another application area is fraud detection. Since, Blockchain is robust and secured, so any alteration to the contents of the degrees, or other documents are highly reduced.

A smart contract typically runs on an Ethernum network. It is a protocol that is similar to a real-contract [19]. It can facilitate contract terms and conditions, negotiate over them, Implement and verify it. It has the identities of the parties involved and thus gets away with the third-party intervention and costs related with them. Smart contracts can be used to give students awards relative to their performance. This can be done by instructors through simple clicks. This award can be in form of crypto-currency which can be stored in e-wallets or virtual wallets. This wallet can be utilized by the student as the need be. Another notable application is in form of fair evaluation specially in collaborative work and assignments. Though, collaborative work is capable of enhancing team-spirit, creative thinking and develop co-operative feeling amongst the peers. But, it has a major down-side. In such assignments, it is often observed that hard-work of one reflects in complete assignment, while the lazy ones bear the fruits of work invested by team-members. Smart contract and Blockchain, together can combat this. Blockchain identifies a block with each student ID. Each team member, submit the work using their own ID, thus, enabling the identification of amount of work done by each. Though, it would be viewed as one entire transaction of the team, but each node shall correspond to each student. The smart contract will then be used to evaluate each student's performance and the results would be stored in the blocks. Also, their opinions and the concept used by each can also be stored as metadata corresponding to each student. This would render a fair-assessment of the entire project. Another application, lies in improvising Student's feedback using blockchain. An instructor would be required to submit a lecture plan at the beginning of a session. This would be like a smart contract. Then, all classroom teaching would be recorded. The consistency of what was designed and the one implemented would be checked using Smart Contract. This verification is done for the contract between the student and the teacher and the teacher and the Academic institution and the teacher. Once completed, Digital rewards in form of cryptocurrencies can be provided to the teachers, in a manner similar to students as discussed above. At higher education, the interaction between the supervisors and the student plays a crucial role in the outcome of research carried out by the scholar. The interaction pattern and the dates on which they interacted, the behavior, and other information can be stored in the blocks. This is non-alterable, as for any alteration, both the parties have to agree. Such a transparent system would enable both the parties to seriously involve themselves in the research, improve the research output, and benefit the society as a whole. 


\subsection{IoT in education}

Internet enabled connected devices are capable of interacting and sharing information which can be analysed and processed to make "intelligent decisions". This gives rise to the Concept called "Internet of Things". The term was used for the first time in 1999 by Kevin Ashton. Since then, it has been re-defined and given several other names and some added concepts. These include Internet of Everything (IoE), Internet of data, Internet of anything, Internet of people, and Internet of Processes [20]. The paper [21], defines it as "anything at all, depending on requirements". The most popular amongst these is IoE, which encompasses people, processes, information, and things which make networked connections reliable and valuable and thus creates new and richer capabilities. It connects various types of devices: laptops, desktops, smartphones, wearable devices, and other hand-held ones. The wearable devices, recognize, adapt, capture the location and the activity being carried out and transmit all the information of its owner. These devices are based on wearable technologies and sensor technology. The wearable technologies are sensor based and can gather information which captures one or more of the following: Mechanical (acceleration, position, displacement, force), Environmental (temperature, humidity), Biological (body-temperature, heart-rate, stress level, oxygen, sleep quality, Blood pressure, e.t.c), Acoustical (Volume, Pitch, timing, Frequency), and Optical Information (brightness, frequency, luminance, e.t.c). This gathered data is then transmitted to other processing units for further processing and decision-making. These interconnected devices could perform the following interactions: Machine to machine (M2M), People to Machine (P2M), and Machine to Machine (M2M). IoT solutions are ubiquitous, and intelligent [22]. So, IoT can be viewed as a physical network that connects devices, and things globally to the Internet Infrastructure to enable communication with both internal and external environment. It enables connectivity of anything at anytime, with anyone using networks, and services [23].

In order to achieve intelligent tracking and managing of things [24], advanced communications, and electronics hold a predictable future [25]. IoT empowers technology and enables professionals in developing small and affordable wireless systems with less power consumption and easy integration to devices [26].

Three major components of IoT which aid in seamless connections are the hardware: comprising of Sensors, wearable devices, actuators, and embedded hardware, the Middleware: comprises of storage, and computational tools which can be used for data analytics, the Presentation: comprises of visualization tools that can be used for different applications [27]. IoT systems communication occurs using wireless technologies like RFID (Radio- Frequency Identification) which has been in use for businesses, protocols like ZigBee, WSN (Wireless Sensor Network) enables wireless sensor capabilities to device, WLAN (Wireless Local Area Network), NFC (Near Field Communication), DSL (Digital Subscriber Line), and others like LTE (Long-Term Evolution) [28] for IoT. Though, IoT has several applications and benefits in the sectors of Healthcare, education, Smart Transportation, Smart Agriculture and others, yet a lot can be explored in the near future.

IoT can enhance the teaching- learning experience in several ways. We need to understand the potential benefits that IoT offers, in education, use its solutions and systems effectively. It shall and is changing the way the educational institutions work, operate 
and function. IoT is being used as a teaching and research medium in education. In [29], the authors describe how Integration of IoT in educational environment facilitates interaction among main actors (teachers and students) and the objects (real and virtual). IoT in the classrooms is an interesting topic particularly as computer science concept [30]. UK open university introduced My Digital Life, as a new course for undergraduate students, which helps students in understanding IoT as a tool for a better understanding [31]. IoT can also be used for a better understanding of Programming language concepts to students [30]. Some other usages of IoT in educational setup using IoT and other technologies can be found in [32-33]. IoT has its application in Task-based learning. IoT has taken a make shift from a knowledge-transfer to a more collaborative, and shared model. In task-based learning, connected systems shall enable the students to self-learn from tasks assigned to them. It also develops team-spirit among them. This also eases the work-load of the teacher in terms of regular monitoring of the students. Besides, it facilitates the learning process, where-in students learn and teachers assist to them. IoT solutions enable feedback, automatic class-room monitoring, and feedbacks. This neither keeps a student in constant touch with the teachers, by sending signals to the teachers, when help required.

This paper [34] discusses, the effective usage of IoT, communication and practical applications of language, enabling task-based learning, targeted for young children. The main purpose of this paper is to motivate students in learning a foreign language. Realistic learning scenarios for foreign language learning using chats, that are studentfriendly, comfortable, and conducive are created. Then using metrics, performances are assessed. IoT can be well utilized for effective feedback analysis. Student's feedback relates to lectures quality. The performance of the teachers improves substantially with the feedbacks received as they help in a deeper understanding of their teaching and communication skills, content delivery, content matter, teaching style, and other parameters and thus, enables them to work upon themselves. In [35], the authors propose a learning environment capable of observing and monitoring student's reactions using sensors while class is going on. Such a monitoring and response system has been found effective in improving a lecture's quality and enhances the understanding level for the students. IoT can be exploited to determine Student's performance which can then be used for effective analysis by the instructors in determining the amount of attention required by each.

Designing of lecture plans, assignments, formative assessments, evaluation of student's performance should be student centric according to the data collected using IoT systems. The study [36] proposes a personalised Teaching \& Learning (UTiLearn) Framework in e-learning environment which exploits IoT, Big Data, and Deep Learning to provide better delivery and management of lessons in smart societies. By analyzing the recorded data, the teaching-learning process can be customized as per the student's retention and absorption level and capacity.

Disabled find difficulty in learning things. Often technological advances have failed in providing support to the disabled students. But, IoT, proves helpful for them. Hearing-impaired students can use devices like connected gloves, and laptops that convert the sign-language to speech, and then converts it into a written form. Such innovations make it possible for them to behave, learn, and perform as any other students does. 
This provides a constructive way leading to significant achievements displayed by the disabled. Also, such disabled student may not be comfortable in the learning space which is well-light, or other types of environmental settings ( say $\mathrm{v}$ low temperature of the room, etc). IoT enables adjustments of the room according to their comfort zone. IoT can easily monitor the usage of several devices in an educational set-up. IoT connected devices, can be programmed, and would auto-generate usage, and performance reports to the teachers and school staff. The teachers can then analyse child-to-child effectiveness in using the resources, like tablets, laptops, etc. Besides, Sensors that indicate movements, and occupancy shall provide useful information on how effectively the room (classroom/ labs/ and library, in particular) has been used. In case, these indicators do not show positive analysis, then, alternate methods or equipment can be used to amuse a student to learn.

IoT in education can enhance the learning experience by making it more engaging and entertaining. Innovative methods, Game-based learning, Interactive sessions, available smart products pave way for a global educational scenario. These can be achieved and supported by Virtual Reality and augmented reality. Both are based on hand- held devices, wearable glasses, and workbench which can project $3 \mathrm{D}$ object onto a table, and several spatial devices which simulate the virtual objects into the real world and it gives us an expression that we are actually touching or feeling it. In [37], the authors use IoT devices to increase the learner's engagement and relies on Multi-Modal learning analytics. Experimental results conducted in a school establish improved motivation and learning capabilities.

In [38], B-Schools have been explored and a model has been built which ensures satisfaction of students by evaluating the determinants of an effective teaching-learning process.

Security becomes a crucial aspect of any domain, and education is no exception to this. Students are plenty and tracking their positions and activities becomes upmost aspect. We all are a witness to killings, and gun- shoots in schools and higher educational institutions. Monitoring of student's behaviour also becomes an important aspect to ponder upon. So, it becomes the duty of the management and staff to keep track of them. IoT can provide solutions for ensuring safety. The rooms (Class-rooms/labs/ libraries) and all other corners of the school can be equipped with necessary devices for the same. Emergency indicators, positioning trackers, wi-fi clocks, audio enhancers, Cameras, etc are some of the IoT solutions that can mitigate the security risk associated with the lives of the students. Wearable devices can be enabled with alarm buttons which can be pressed to caution the authorities in case a student faces a danger at any point in the school. This could also be sued, in-case a lift poses a danger and is not man-operated. Though, lifts have certain guidelines to be followed, but in reality, a few institutions do not follow them and the students can be at a risk. Special emergency alarm tones, live bulletins, can also be an aid, when some malicious activity is detected in the institution.

Attendance tracking is a time-consuming task and IoT can save time. RFID tags, are in particular of great usage in tracking attendance. A robust system can reduce the load and time invested in preparing sheets and involves human-error too. But, IoT solutions can auto generate and record attendance and also keep the parents and guardians alert 
about their child's absence or presence in the institution. This can be done by sending SMS, or emails to registered data maintained by the school/college. In [39], NFC technology using smartphones monitors the attendance of the student. Besides, Smart Homes, smart Transportation, and Smart classrooms are the new norm. Smart environment [40] forms an integral part of these. "Smart Environment" senses temperature, humidity, air flow, etc using sensors, and automatically tracks, adjusts and optimizes the space. The Lights, and the HVAC setting (Heating, ventilation, and air conditioning) can be adjusted according to the room's occupancy and usage. These adjustments should also be done on the basis of the way they are utilized. A lab requirement will vary from a dance room or an auditorium. These features are programmed and also used efficiently to reduce energy wastage and thus results in substantial cost cutting. Smart Classroom or the Smart campus both, have all the functionalities mentioned above depending on whether IoT solution is being used for a class environment or a campus. An ideal smart Campus has been shown in Figure 2 [41].

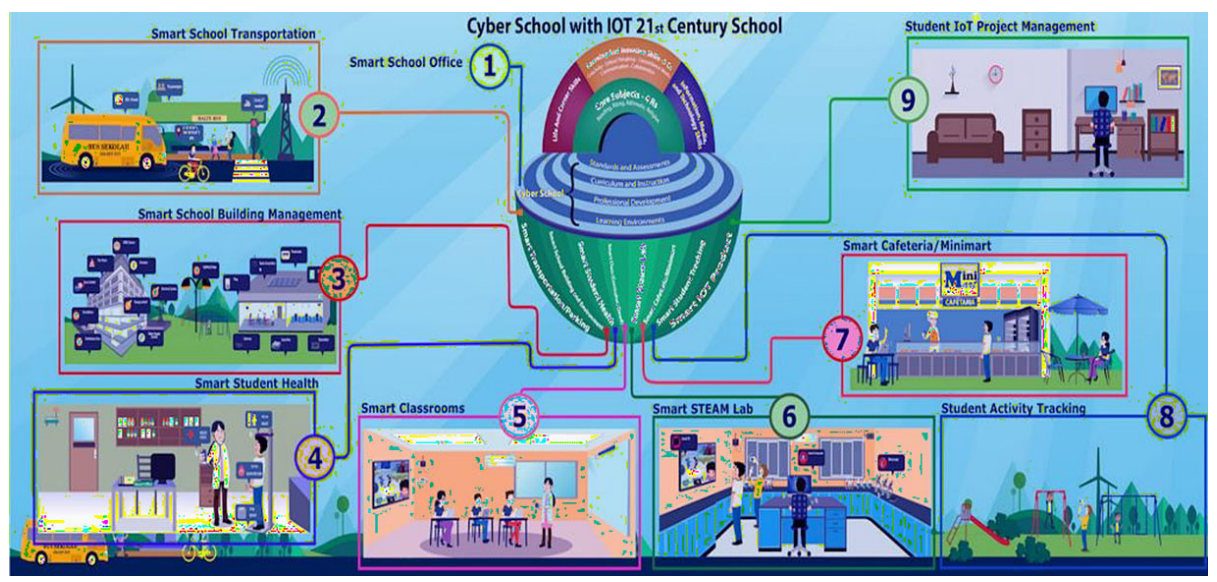

Fig. 2. IoT enabled smart campus

Some applications of both IoT and Blockchain have been summarized in Table 1.

Table 1. Applications of Blockchain and IoT in education

\begin{tabular}{|l|c|l|}
\hline \multicolumn{1}{|c|}{ S.No. } & Study Involved & \multicolumn{1}{c|}{ Applications } \\
\hline 2 & {$[42-45]$} & Learning outcome management \\
\hline 3 & {$[46]$} & Learning is Earning concept \\
\hline 4 & {$[47]$} & Self-paced learning \\
\hline 5 & {$[48-49]$} & classroom environment and health monitoring \\
\hline 6 & {$[50]$} & Customized learning \\
\hline 7 & {$[51]$} & Credit and fees transfer \\
\hline 8 & {$[52]$} & Examinations review \\
\hline 9 & {$[53-54]$} & Collaborative work environment \\
\hline
\end{tabular}


This section clearly discussed the applications and associated benefits of both Blockchain technology and IoT in education. The next section discusses the barriers associated with their adoption, deployment and implementation.

\section{Challenges}

This section aims to explore and identify the impediments encountered in integrating these technologies with the education sector.

\subsection{Blockchain in education}

Blockchain technology has several benefits to offer. Security and privacy remain major issues with blockchain. As privacy increases, the availability and accessibility of data decreases specially for those sites that depend on user's data. Malicious attacks [55], and data leakage as a result of frequent up-dation of data [56] need to be handled. Blockchain framework uses Public-key cryptography, and thus relies on usage of both public keys and private keys. But, data of public key is visible [57] and can be used to identify user's information. Enough storage as well as protection of private keys is a crucial issue too and needs to be handled [58]. It is well understood that blockchain is one block mapping for each transaction. Thus, as transactions increase, the block size begins to grow substantially with increase in number of users [59-60]. The slow transaction speed and management of data are additional issues. Blockchain is still young, so its adoption and implementation poses high costs. As said, management of huge data being generated and its storage, results in a growing cost [61]. The terminologies, complex settings associated with blockchain, lack of clarity, poor usability, lack of technical expertise to use this system by stakeholders do not make the system easy to use. Authorized educational institutions may not be ready to share their student's credentials, and this can lead to a complicated authorization process [62]. Blockchain is immutable. This feature prevents the governments to perform any changes in defined policies of a system, or may require an access or change in the data for maintaining law and order situation.

\subsection{IoT in education}

Implementation of IoT solutions for the education sector requires large hardware as well as software power. Accessing, deploying and maintenance of these solutions is required. A well skilled technical team is required for this work. The above issues incur high cost. The IoT products, their buying cots, license fees and an additional maintenance fees unfortunately adds to the total cost which make it unaffordable for all. Implementation of IoT solutions too needs reliable computing platforms and robust data tools and techniques. Besides, these solutions and data storage techniques adopted by institutions should not be outdated as they may not be able to provide a good connected IoT network. A few of these issues have been addressed in [63]. Also, collection and processing of data collected through IoT devices makes it vulnerable 
to hacking threats. Increased awareness about data security forms an important aspect for all stakeholders. A few measures that can be adopted by them are conscious use of data, frequent change of passwords and device updates and system checkers might prevent the cybersecurity threats posed by malicious applications trying to access the sensitive data. Weak protocols and policies, their inappropriate documentation [64] too are responsible for a non-robust framework. Since 2008, well-developed phishing techniques provoked the individuals to share their sensitive data [65], 5G shall bring about several revolutionary changes in the way we use IoT systems, applications and solutions. It shall change the way in which IoT is used in every sector including education. High bandwidth, and frequency shall open avenues and increase the accessibility for all stake holders of this sector. But, it would also require setting up of substantial number of base stations. This would increase the threats multi-fold as more fake stations would come up imposing more problems which would be surely difficult to handle. In [66], the authors mention a few challenges which include spoofing, jamming, and similar ones that breach the integrity of data. IoT technologies are also gripped with several ethical problems. IoT is a global framework that connects the devices and exploits data by capturing it using wearable devices, and other technologies. It thus, heavily relies on $3 \mathrm{G}, 4 \mathrm{G}$, sensor technology, and others for this purpose. This data collected can be misused by educational institutions for some analysis and derive benefits. Since IoT offers a global sharing platform so IoT based tools nay encourage cheating, and other types of academic dishonesty. A few of the ethical issues have been discussed in [67]. High speed network bandwidth is surely a necessity for the IoT framework to function properly but not everywhere it is possible, Education is a fundamental right and it is through these technologies that outreach can be expanded. But at the same time, making it available with an active Internet connection at high speed, is a gap that needs to be filled. Environmental issue IoT relies heavily on sensors and wearable devices. This generates lots of E-waste and proves to be hazardous for the environment. To decrease the effects on environment this paper [68] discusses how IoT can be transformed to tackle its negative impact and transform IoT to Green IoT. IoT requires skilled hands for its deployment and maintenance. But The stakeholders specially the teachers need to ne provided training for its usage. These have been discussed in [69-70].

\section{Conclusion}

Thus, it has been identified that Blockchain: a decentralized digital ledger, is secure, reliable, and immutable. Owing to these characteristics and its applications in the Education sector, it can be fully exploited to enhance the entire teaching-learning process, provide fair-evaluation of both students and teachers, improve the performance, motivate both students and teachers by giving them rewards, management of records, fraud detection, and others. These applications with some new innovative models and ideas can pave the way for a better future for the education sector. The challenges associated with Blockchain should be overcome, and future research work would yield better results. Besides, IoT pledges to improve the quality of life of students and teachers. The information gathered from sensing devices helps to continuously monitor each student activities, mood, health, behaviour, contribution in the class and thus allows fair-assessment and generate Student-centric response accordingly. An efficient and 
rapid teaching-learning process is enabled and it was identified through this study that IoT plays a major role for this. Though, IoT, is also gripped with certain barriers, which should be overcome, and in the future, integrated framework, that combine the benefits of both Blockchain and IoT, shall help to achieve a better future for the education sector.

\section{$5 \quad$ References}

[1] Bagheri, M. and Movahed, S. H. "The Effect of the Internet of Things (IoT) on Education Business Model," 2016 12th International Conference on Signal-Image Technology \& Internet-Based Systems (SITIS), 2016, pp. 435-441, doi: https://doi.org/10.1109/SITIS.2016.74

[2] Yumna, H., Khan, M. M., Ikram, M., and Ilyas, S. (2019). Use of Blockchain in Education: A Systematic Literature Review. In: Nguyen N., Gaol F., Hong T. P., Trawiński B. (eds) Intelligent Information and Database Systems. ACIIDS 2019. Lecture Notes in Computer Science, vol 11432. Springer, Cham. https://doi.org/10.1007/978- 3-030-14802-7 17

[3] Chen, L. Chen, P., and Lin, Z. "Artificial Intelligence in Education: A Review," in IEEE Access, vol. 8, pp. 75264-75278, 2020, doi: https://doi.org/10.1109/ACCESS.2020.2988510

[4] Qassim, H. (2020). Using of Cloud Computing in Education. International Journal of Engineering Science and Computing, 8(9), pp 18934-18939.

[5] Idrees, S. M., Aijaz, I., Jameel, R., and Nowostawski, M. (2021). Exploring the Blockchain Technology: Issues, Applications and Research Potential. International Journal of Online \& Biomedical Engineering, 17(7). https://doi.org/10.3991/ijoe.v17i07.22803

[6] Nakamoto, S. (2008). Bitcoin:APeer-to-Peer Electronic Cash System. Available online at: https://git.dhimmel.com/bitcoin-whitepaper/ (accessed August 3, 2020).

[7] Treleaven, P., Gendal Brown, R., and Yang, D. (2017). Blockchain technology in finance. Computer 50, 14-17. doi: https://doi.org/10.1109/MC.2017.3571047

[8] Roeck, D., Schöneseiffen, F., Greger, M., and Hofmann, E. (2020). "Analyzing the Potential of DLT-based Applications in Smart Factories," in Blockchain and Distributed Ledger Technology Use Cases-Applications and Lessons Learned, eds H. Treiblmaier and T. Clohessy (Cham: Springer), 245-266. https://doi.org/10.1007/978-3-030-44337-5 12

[9] Zhu, X., and Badr, Y. (2018). Identity management systems for the internet of things: a survey towards blockchain solutions. Sensors 18:4215. doi: https://doi.org/10.3390/s18124215

[10] Huh, S., Cho, S., and Kim, S. (2017). "Managing IoT Devices using Blockchain Platform," in Proceedings of the 19th International Conference on Advanced Communication Technology (Piscataway, NJ: IEEE), 464-467.

[11] ]Dorri, A., Kanhere, S., and Jurdak, R. (2017). "Towards an Optimized BlockChain for IoT," in Proceedings of the IEEE/ACM Second International Conference on Internet-of-Things Design and Implementation (Piscataway, NJ: IEEE), 173-178.

[12] Kumar Singh, S., Rathore, S., and Park, J. H. (2020). BlockIoTIntelligence: a blockchainenabled intelligent IoT architecture with artificial intelligence. Future Generation Comput. Syst. 110, 721-743. doi: https://doi.org/10.1016/j.future.2019.09.002

[13] Underwood, S. Blockchain beyond Bitcoin. Commun. ACM 59(11), 15-17 (2016). https:// doi.org/10.1145/2994581

[14] Collins, R. Blockchain: A new architecture for digital content. EContent 39(8), 22-23 (2016)

[15] Devine, P. Blockchain learning: can crypto-currency methods be appropriated to enhance online learning? Presented at the ALT Online Winter Conference 2015, Online, (United Kingdom, 2015)

[16] Chaari, M. Z., and Al-Maadeed, S. (2021). Increase the Efficiency of IoT Devices by Using the Wireless Power Transmission in the Industrial Revolution 4.0. International Journal of Online \& Biomedical Engineering, 17(7). https://doi.org/10.3991/ijoe.v17i07.24143 
[17] Yli-Huumo, J., Ko, D., Choi, S., Park, S., and Smolander, K. Where is current research on Blockchain technology? A systematic review. PLoS One 11(10), e0163477 (2016). https:// doi.org/10.1371/journal.pone.0163477

[18] Han, M., Li, Z., He, J. S., Wu, D., Xie, Y., and Baba, A. A Novel Blockchain-based Education Records Verification Solution. In Proceedings of the 19th Annual SIG Conference on Information Technology Education, Fort Lauderdale, FL, USA, 3-6 October 2018; pp. 178-183. https://doi.org/10.1145/3241815.3241870

[19] Kosba, A., Miller, A., Shi, E., Wen, Z., and Papamanthou, C., in 2016 IEEE Symposium on Security and Privacy (SP). Hawk: The Blockchain Model of Cryptography and Privacy-Preserving Smart Contracts (2016), pp. 839-858. https://doi.org/10.1109/SP.2016.55

[20] Cornel C., and Ph, D. "The Role of Internet of Things for a Continuous Improvement in Education," vol. 2, no. 2, pp. 24-31, 2015.

[21] Oriwoh E., and Conrad, M. "Things" in the Internet of Things :TowardsaDefinition," vol. 4, no. 1, pp. 1- 5, 2015.

[22] Kahlert, M., Understanding customer acceptance of Internet of Things services in retailing: an empirical study about the moderating effect of degree of technological autonomy and shopping motivations. 2016, University of Twente.

[23] Friess, P. Internet of things: converging technologies for smart environments and integrated ecosystems. 2013: River Publishers.

[24] Stankovic, J. A. Research directions for the internet of things. IEEE Internet of Things Journal, 2014. 1(1): p. 3-9. https://doi.org/10.1109/JIOT.2014.2312291

[25] Agarwal, S., and S. Pati, Study of Internet of Things. International Journal for Scientific Research \& Development, 2016. 4(05): p. 4.

[26] Jin, D. Application of" Internet of Things" in Electronic Commerce. International Journal of Digital Content Technology \& its Applications, 2012. 6(8). https://doi.org/10.4156/jdcta. vol6.issue 8.26

[27] Gubbi, J., et al., Internet of Things (IoT): A vision, architectural elements, and future directions. Future Generation Computer Systems, 2013. 29(7): p. 1645-1660. https://doi.org/ $\underline{10.1016 / j . f u t u r e .2013 .01 .010}$

[28] Marques, G., Garcia, N., and Pombo, N. "Advances in Mobile Cloud Computing and Big Data in the 5G Era," vol. 22, pp. 115-130, 2017. https://doi.org/10.1007/978-3-319-45145-9 5

[29] Marquez, J., Villanueva, J., Solarte, Z., and Garcia, A. "IoT inEducation :IntegrationofObjectswith Virtual Academic Communities," in New Advances in Information Systems and Technologies, no. 115, Springer International Publishing, 2016, pp. 201-212. https://doi. org/10.1007/978-3-319-31232-3_19

[30] Chin, J., and Callaghan, V. "Educational living labs: A novel internet-of-things based approach to teaching and research," Proc. - 9th Int. Conf. Intell. Environ. IE 2013, pp. 92-99, 2013. https://doi.org/10.1109/IE.2013.48

[31] Barakat, S, "Education and the internet of everything, Int. Bus. Manag., vol. 10, no. 18, pp. 4301-4303, 2016.

[32] Castellani, A. P., Bui, N., Casari, P., Rossi, M., Shelby, Z., and Zorzi, M. "Architecture and Protocols for the Internet of Things: A Case Study," Pervasive Computing and Communications Workshops (PERCOM). 2010. https://doi.org/10.1109/PERCOMW.2010.5470520

[33] Chen, Y., and Dong, X. "The Development and Prospect of New Technology in Modern distance education,” Int. Conf. Inf. Sci. Comput. Appl., pp. 40-44, 2013. https://doi.org/ 10.2991/isca-13.2013.7

[34] E. de la Guía, V. L. Camacho, L. Orozco-Barbosa, V. M. Brea Luján, V. M. R. Penichet and M. Lozano Pérez, "Introducing IoT and Wearable Technologies into Task-Based Language Learning for Young Children," in IEEE Transactions on Learning Technologies, vol. 9, no. 4, pp. 366-378, 1 Oct.-Dec. 2016, doi: https://doi.org/10.1109/TLT.2016.2557333 
[35] Chew, C. B. "Sensors-Enabled Smart Attendance Systems Using Nfc and Rfid Technologies," Int. J. New Comput. Archit. their Appl., vol. 5, no. 1, pp. 19-28, 2015. https://doi.org/ 10.17781/P001645

[36] Mehmood, R., Alam. Furqan, N., N., Albogami, Katib, I., Albeshri, A., and Altowaijri, S. (2017). UTiLearn: A Personalised Ubiquitous Teaching and Learning System for Smart Societies. IEEE Access PP(99):1-1. https://doi.org/10.1109/ACCESS.2017.2668840

[37] Camacho, V. L., de la Guía, E., Olivares, T., Flores, M. J., \& Orozco-Barbosa, L. (2020). Data Capture and Multimodal Learning Analytics Focused on Engagement With a New Wearable IoT Approach. IEEE Transactions on Learning Technologies, 13(4), 704-717. https://doi.org/10.1109/TLT.2020.2999787

[38] Rastogi, S., Sharma, A., and Panse, C. P. (2019). Changing facets of higher education in management: a students' perspective. International Journal of Educational Management. https://doi.org/10.1108/IJEM-07-2018-0196

[39] Alghamdi, A., and Shetty, S. "Survey toward a smart campus using the internet of things," in Proceedings - 2016 IEEE 4th International Conference on Future Internet of Things and Cloud, FiCloud 2016, 2016, pp. 235-239. https://doi.org/10.1109/FiCloud.2016.41

[40] Youngblood, G. M., Heierman, E. O., Holder, L. B., \& Cook, D. J. (2005, August). Automation intelligence for the smart environment. In International Joint Conference On Artificial Intelligence (Vol. 19, p. 1513). Lawrence Erlbaum Associates Ltd.

[41] Team, D. (2021, May 9). 6 Important Roles \& Application of IoT in Education. DataFlair. Retrieved November 9, 2021, from https://data-flair.training/blogs/iot-in-education/; Available at: https://d2h0cx97tjks2p.cloudfront.net/blogs/wp-content/uploads/sites/2/2018/05/ iot-edu-image-3.png

[42] Skiba, D. J. The potential of Blockchain in education and health care. Nurs. Educ. Perspect. 38(4), 220-221 (2017). https://doi.org/10.1097/01.NEP.0000000000000190

[43] Hoy, M. B. An introduction to the Blockchain and its implications for libraries and medicine. Med. Ref. Serv.Q. 36(3), 273-279 (2017). https://doi.org/10.1080/02763869.2017.1332261

[44] Tariq, A. "Cerberus: A Blockchain-Based Accreditation and Degree VerificationSystem." ArXiv abs/1912.06812 (2019): n. pag

[45] Nespor, J. Cyber schooling and the accumulation of school time. Pedag. Cult. Soc. 2018, $1-17$.

[46] Sharples, M., and Domingue, J. in The Blockchain and Kudos: A Distributed System for Educational Record, Reputation and Reward. Adaptive and adaptable learning (Springer, Cham, 2016), pp. 490-496. https://doi.org/10.1007/978-3-319-45153-4_48

[47] Aldowah, H., S. Ghazal, S., and Muniandy, B. Issues and Challenges of Using E-Learning in a Yemeni Public University. Indian Journal of Science and Technology, 2015. 8(32). https://doi.org/10.17485/ijst/2015/v8i32/92160

[48] Sharma, P. K., De, T., and Saha, S. "IoT based indoor environment data modelling and prediction," 2018 10th International Conference on Communication Systems \& Networks (COMSNETS), 2018, pp. 537-539, doi: https://doi.org/10.1109/COMSNETS.2018.8328266

[49] Francisti, J., Balogh, Z., Reichel, J., Magdin, M., Koprda, Š., and Molnár, G. Application Experiences Using IoT Devices in Education. Applied Sciences. 2020; 10(20):7286. https:// doi.org/10.3390/app10207286

[50] Spyrou, E., Vretos, N., Pomazanskyi, A., Asteriadis, S., and Leligou, H. C. "Exploiting IoT Technologies for Personalized Learning," 2018 IEEE Conference on Computational Intelligence and Games (CIG), 2018, pp. 1-8, doi: https://doi.org/10.1109/CIG.2018.8490454

[51] Wu, B., and Li, Y. Design of Evaluation System for Digital Education Operational Skill Competition Based on Blockchain. In Proceedings of the 2018 IEEE 15th International Conference on e-Business Engineering (ICEBE), Xi'an, China, 12-14 October 2018; pp. 102-109. https://doi.org/10.1109/ICEBE.2018.00025 
[52] Mitchell, I., Hara, S., and Sheriff, M. dAppER: Decentralised Application for Examination Review. In Proceedings of the 2019 IEEE 12th International Conference on Global Security, Safety and Sustainability (ICGS3), London, UK, 16-18 January 2019; pp. 1-14. https://doi. org/10.1109/ICGS3.2019.8688143

[53] Bdiwi, R., De Runz, C., Faiz, S., and Cherif, A. A. A Blockchain Based Decentralized Platform for Ubiquitous Learning Environment. In Proceedings of the 2018 IEEE 18th International Conference on Advanced Learning Technologies (ICALT), Mumbai, India, 9-13 July 2018; pp. 90-92. https://doi.org/10.1109/ICALT.2018.00028

[54] Zhong, J., Xie, H., Zou, D., and Chui, D. K. A Blockchain Model for Word-Learning Systems. In Proceedings of the 2018 5th International Conference on Behavioral, Economic, and Socio-Cultural Computing(BESC), Kaohsiung, Taiwan, 12-14 November 2018; pp. 130-131. https://doi.org/10.1109/BESC.2018.8697299

[55] Zheng, Z., Xie, S., Dai, H., Chen, X., and Wang, H. An overview of blockchain technology: Architecture, consensus, and future trends. In Proceedings of the 2017 IEEE International Congress on Big Data (BigData Congress), Honolulu, HI, USA, 25-30 June 2017; pp. 557-564. https://doi.org/10.1109/BigDataCongress.2017.85

[56] Gilda, S., and Mehrotra, M. Blockchain for Student Data Privacy and Consent. In Proceedings of the 2018 International Conference on Computer Communication and Informatics, Coimbatore, India, 4-6 January 2018; pp. 1-5. https://doi.org/10.1109/ICCCI.2018.8441445

[57] Farah, J. C., Vozniuk, A., Rodríguez-Triana, M. J., and Gillet, D. A Blueprint for a Blockchain-Based Architecture to Power a Distributed Network of Tamper-Evident Learning Trace Repositories. In Proceedings of the 2018 IEEE 18th International Conference on Advanced Learning Technologies (ICALT), Mumbai, India, 9-13 July 2018; pp. 218-222. https://doi.org/10.1109/ICALT.2018.00059

[58] Turkanovic', M., Hölbl, M., Košič, K., Heric ``ko, M., and Kamišalic', A. EduCTX: Ablockchain-based higher education credit platform. IEEE Access 2018, 6, 5112-5127. https://doi. org/10.1109/ACCESS.2018.2789929

[59] Han, M., Li, Z., He, J. S., Wu, D., and Xie, Y. Baba, A. A Novel Blockchain-based Education Records Verification Solution. In Proceedings of the 19th Annual SIG Conference on Information Technology Education, Fort Lauderdale, FL, USA, 3-6 October 2018; pp. 178-183. https://doi.org/10.1145/3241815.3241870

[60] Xu, Y., Zhao, S., Kong, L., Zheng, Y., Zhang, S., and Li, Q. ECBC: A high performance educational certificate blockchain with efficient query. In Proceedings of the International Colloquium on Theoretical Aspects of Computing, Hanoi, Vietnam, 23-27 October 2017; pp. 288-304. https://doi.org/10.1007/978-3-319-67729-3_17

[61] Idrees, S. M., Alam, M. A., and Agarwal, P. (2019). A study of big data and its challenges. International Journal of Information Technology, 11(4), 841-846. https://doi.org/ $10.1007 / \mathrm{s} 41870-018-0185-1$

[62] Wanotayapitak, S., Saraubon, K., \& Nilsook, P. (2019). Process Design of Cooperative Education Management System by Cloud-based Blockchain E-portfolio. International Journal of Online \& Biomedical Engineering, 15(8). https://doi.org/10.3991/ijoe.v15i08.10374

[63] Makhdoom, I., Abolhasan, M., Lipman, J., Liu, R. P., and Ni, W. Anatomy of threats to the Internet of things. IEEE Commun. Surv. Tutor. 2018, 21, 1636-1675. https://doi. org/10.1109/COMST.2018.2874978

[64] Conti, M., Dehghantanha, A., Franke, K., and Watson, S. Internet of Things security and forensics: Challenges and opportunities. Future Gener. Comput. Syst. 2018, 78, 544-546. https://doi.org/10.1016/j.future.2017.07.060

[65] Monther, A. A., and Tawalbeh, L. Security techniques for intelligent spam sensing and anomaly detection in online social platforms. Int. J. Electr. Comput. Eng. 2020, 10, 2088-8708. https://doi.org/10.11591/ijece.v10i1.pp275-287 
[66] Siby, S., Maiti, R. R., and Tippenhauer, N. O. Iotscanner: Detecting privacy threats in IoT neighborhoods. In Proceedings of the 3rd ACM International Workshop on IoT Privacy, Trust, and Security, Abu Dhabi United Arab Emirates, 2 April 2017; pp. 23-30. https://doi. org $/ 10.1145 / 3055245.3055253$

[67] Internet Of Things-Some Ethical Issues. Available from: https://www.researchgate.net/publication/260290933_Internet_Of Things-Some_Ethical_Issues [accessed May 02 2021].

[68] Radu, L-D, (2018), Environmental Issues in Internet of Things: Challenges and Solutions, Acta Universitatis Danubius. OEconomica, issue 14(1), pp. 20-32.

[69] Maryam, B., and Siavosh, H. M. The Effect of the Internet of Things (IoT) on Education Business Model, $12^{\text {th }}$ International Conference on Signal-Image Technology \& Internet-Based Systems, 2016 https://doi.org/10.1109/SITIS.2016.74

[70] Daniela P., and Mircea G. Internet of Things - Some Ethical Issues, The USV Annals of Economics and Public Administration, Volume 13, Issue 2(18), 2013.

\section{Authors}

Parul Agarwal Parul Agarwal is associated with Jamia Hamdard since 2002. She is currently an Associate Professor in the Department of Computer Science and Engineering. Her area of specialization include Fuzzy Data Mining, Cloud Computing, Sustainable computing, and Soft Computing. Her particular interest includes applications of Sustainable Computing in Agriculture, transportation and health care. She has published several papers in reputed and SCI, Scopus and Elsevier indexed journals and many book chapters published by CRC press, Springer, IGI-Global are to her credit. She is Editor of three edited volumes to be published by CRC press, and Springer. She has chaired several sessions of International/ National Conferences of repute.

Sheikh Mohammad Idrees Sheikh Mohammad Idrees received his Ph.D. Degree from the Department of Computer Science, Jamia Hamdard, New Delhi. He is currently working as a Postdoctoral Fellow at Department of Computer Science (IDI), Norwegian University and Science and Technology (NTNU) Norway. He is the recipient of Alain Bensoussan Fellowship award under European Research Consortium for Informatics and Mathematics, Sophia Antipolis Cedex, France. He has authored and co-authored several scientific publications in well reputed journals and international conferences. He is also a frequent book editor of Springer and CRC Press (Taylor and Francis group) apart from being a frequent contributor and reviewer of various reputed international journals and conferences.

Ahmed J. Obaid Ahmed J. Obaid, is a full assistant professor at the Department of Computer Science, Faculty of Computer Science and Mathematics, University of Kufa, He received his BSC in Information Systems (IS) in 2005, from faculty of computer science, University of Anbar in 2005. M.Tech in Computer Science and Engineering from SIT, JNTUH, India in 2012, and PhD in Web Mining and Data Mining from University of Babylon in 2017. His main line of research is Web mining Techniques and Application, Image processing in the Web Platforms, Image processing, Genetic Algorithm and information theory.

Article submitted 2021-06-23. Resubmitted 2021-08-10. Final acceptance 2021-08-11. Final version published as submitted by the authors. 